\title{
Distribution and structure of glandular tissue in the oropharynx and proximal esophagus of the emu (Dromaius novaehollandiae)
}

\author{
Martina R. Crole* and John T. Soley \\ Department of Anatomy and Physiology, Faculty of Veterinary Science, University of Pretoria, Private Bag X04, Onderstepoort, 0110 \\ South Africa
}

\begin{abstract}
The glandular regions of the upper digestive tract in the emu were non-pigmented (except for the tongue in most specimens) and invested by a non-keratinised stratified squamous epithelium. The glands found in these regions were exclusively simple in nature and composed of tubular secretory units lined by Periodic Acid Schiff Stain-positive mucus-secreting cells. The naming of the various glandular fields was based on previously identified anatomical features and on nomenclature modified from previous studies on birds. The glands were classified into two main types, namely, simple tubular and simple branched tubular mucus-secreting glands. Simple branched tubular glands were a feature of the regions exposed to the greatest amount of friction during feeding, whereas simple tubular glands were a feature of regions exposed to less friction. The saliva produced by the salivary glands in birds functions to moisturize and lubricate food boli. Mucins in saliva also protect mucosal surfaces from desiccation and mechanical damage, assist in maintaining cellular water balance, provide lubrication and have an antimicrobial action. This study suggests that, in addition to the role of specific gross anatomical features, the type and distribution of glandular tissue in the emu upper digestive tract supports the cranioinertial feeding method employed by this species.
\end{abstract}

Keywords: emu, oropharynx, glands, distribution, structure

\section{Introduction}

Glandular tissue is a characteristic feature of the upper digestive tract of birds and this tissue has been identified in numerous avian species (Antony 1920; Fahrenholz 1937; Tucker 1958; Warner et al. 1967; McLelland 1975, 1979; King and McLelland 1984; Samar et al. 1999; Al-Mansour and Jarrar 2004; Jackowiak and Godynicki 2005; Porchescu 2007) including domestic poultry (McLeod 1939; Calhoun 1954; Saito 1965; Ziswiler and Farner 1972 ; Hodges 1974; Nickel et al. 1977; King and McLelland 1984; Porchescu 2007). Contradictory evidence has been presented regarding the relative amounts of glandular tissue present in the oropharynx of birds. Salivary glands are reportedly best developed in birds which consume a dry diet (King and McLelland 1984).

However, reports exist of birds with well-developed glands which consume a naturally lubricated diet (Samar et al 1999). In some species glandular tissue is entirely absent (Antony 1920) while others display a seasonal change in gland size (McLelland 1979).

Two types of salivary glands occur in birds, namely, monostomatic and polystomatic glands (Fahrenholz 1937). Polystomatic glands are composed of a large number of independent glandular units which together form a glandular field (Fahrenholz 1937). The less common monostomatic salivary glands are compound in nature (Tucker 1958), form definitive structures and are represented by the oral angular and maxillary glands, particularly in poultry (Fahrenholz 1937; Saito 1965; Nickel et al. 1977; McLelland 1979). Although glandular tissue has been reported in the upper digestive tract of most birds, there appears to be a lack of consensus and uniformity regarding the extent and naming of the various glandular fields (see, for example Antony 1920; Tucker 1958 and Saito 1965). In addition, despite reports that tubular glands are the most common type found in birds (Fahrenholz 1937; Ziswiler and Farner

\footnotetext{
* Martina R. Crole, Department of Anatomy and Physiology, Faculty of Veterinary Science, University of Pretoria, Private Bag
} X04, Onderstepoort 0110, South Africa. E-mail: martina.crole@up.ac.za 
1972) and that they appear morphologically similar in all species, they have been described alternatively as simple branched tubular, tubulo-alveolar, alveolar and complex alveolar glands (Calhoun 1954; Warner et al 1967; Hodges 1974; McLelland 1975, 1979; Samar et al. 1999).

Studies on the upper digestive tract of ratites have identified glandular tissue in the ostrich (Struthio camelus) (Porchescu 2007; Jackowiak and Ludwig 2008; Tivane 2008), greater rhea (Rhea americana) (Feder 1972) and emu (Dromaius novaehollandiae) (Herd 1985; Crole and Soley 2009a, b, c, 2010b). However, with the exception of a detailed report on the lingual glands of the emu (Crole and Soley 2009c) very little comprehensive information is available on the morphology and distribution of glandular tissue in the oropharynx and proximal esophagus in this group of birds.

The saliva produced by the salivary glands in birds is important for maintaining the health of the upper digestive tract and for the ingestion of food. Mucins which form a component of the mucus produced by the salivary glands protect the surfaces of the upper digestive tract against dessication, mechanical damage and the action of microbes, while also providing lubrication of food boli (Tabak et al 1982). The emu is a commercially important bird and is reported to have a varied diet (Davies 1978) which is relatively dry in nature. In common with other ratites, the emu employs a particular feeding method whereby the food is thrown caudal to the laryngeal mound prior to it being swallowed (Bonga Tomlinson 2000; Gussekloo and Bout 2005). While the particular gross anatomical features of the emu upper digestive tract have previously been linked to the above mentioned feeding method (Crole and Soley 2010a), it may also be suggested that the amount and distribution of glandular tissue in the emu oropharynx would support the specific diet and feeding strategy of this species. In view of the important role that glandular tissue plays in the efficient functioning of the upper digestive tract of birds, this paper characterizes the morphology of the glands in the oropharynx and proximal esophagus of the emu and also maps their distribution. A platform is also laid for future comparative studies on gland distribution and function in the ratite upper digestive tract.

\section{Materials and Methods}

The heads of eight sub-adult (14-15 months) emus of either sex were obtained from local abattoirs (Oryx Abattoir, Krugersdorp, Gauteng Province and Emu Ranch, Rustenburg, North-West Province, South Africa) immediately after slaughter of the birds. The heads were rinsed in running tap water to remove traces of blood and then immersed in plastic buckets containing $10 \%$ neutral-buffered formalin. The heads were allowed to fix for approximately four hours while being transported to the laboratory, after which they were immersed in fresh fixative for a minimum period of 48 hours. Care was taken to exclude air from the oropharynx by wedging a small block of wood between the rostral billtips.

After rinsing the heads in running tap water, the right commissure of the beak was incised and the mandible reflected laterally by disarticulating the quadratomandibular joint to openly display the roof and floor of the oropharynx and the proximal esophagus (Fig. 1). Samples for histology were removed from one half of the floor and roof of the oropharynx of five heads. Each half side was divided into morphologically identifiable regions (described by Crole and Soley 2010a) which were sampled in the transverse plane at regular intervals of about $5 \mathrm{~mm}$ (Fig. 1). The proximal esophagus was sampled in two regions (Fig. 1). The samples were dehydrated through $70,80,96$, and $2 x 100 \%$ ethanol and further processed through 50:50 ethanol: xylol, 2x xylol and 2· paraffin wax (60-120 minutes per step) using a Shandon model 2LE Automatic Tissue Processor (Shandon, Pittsburgh, PA, USA). Tissue samples were then imbedded manually into paraffin wax in plastic moulds. Sections were cut at 4-6 $\mu \mathrm{m}$, stained with Haematoxylin and Eosin and Periodic Acid Schiff Stain (PAS) (McManus 1946) and viewed and micro-graphed using an Olympus BX50 equipped with the analysis CC12 Soft Imaging System (Olympus, Japan). Undiluted Indian ink was applied to the surface of the entire oropharynx and proximal esophagus of the remaining three heads. The ink was lightly rubbed onto the surface and left to stand for 2 minutes, after which it was rinsed off under running water. The surface was then examined by stereomicroscopy to determine the distribution of the ink-filled gland openings.

The terminology used in this study is that of Nomina Anatomica Avium (Baumel et al 1993).

\section{Results}

\section{Gland distribution and structure}

With the exception of the tongue, which was variably pigmented, the pigmented regions of the oropharynx (rostral part of the roof, maxillary and mandibular rhamphotheca and rostral interramal region) (Fig. 1) were invested by a keratinised stratified squamous epithelium and were aglandular. The remaining parts of the oropharynx (essentially the non-pigmented regions but including the tongue) were lined by a non-keratinised stratified squamous epithelium 


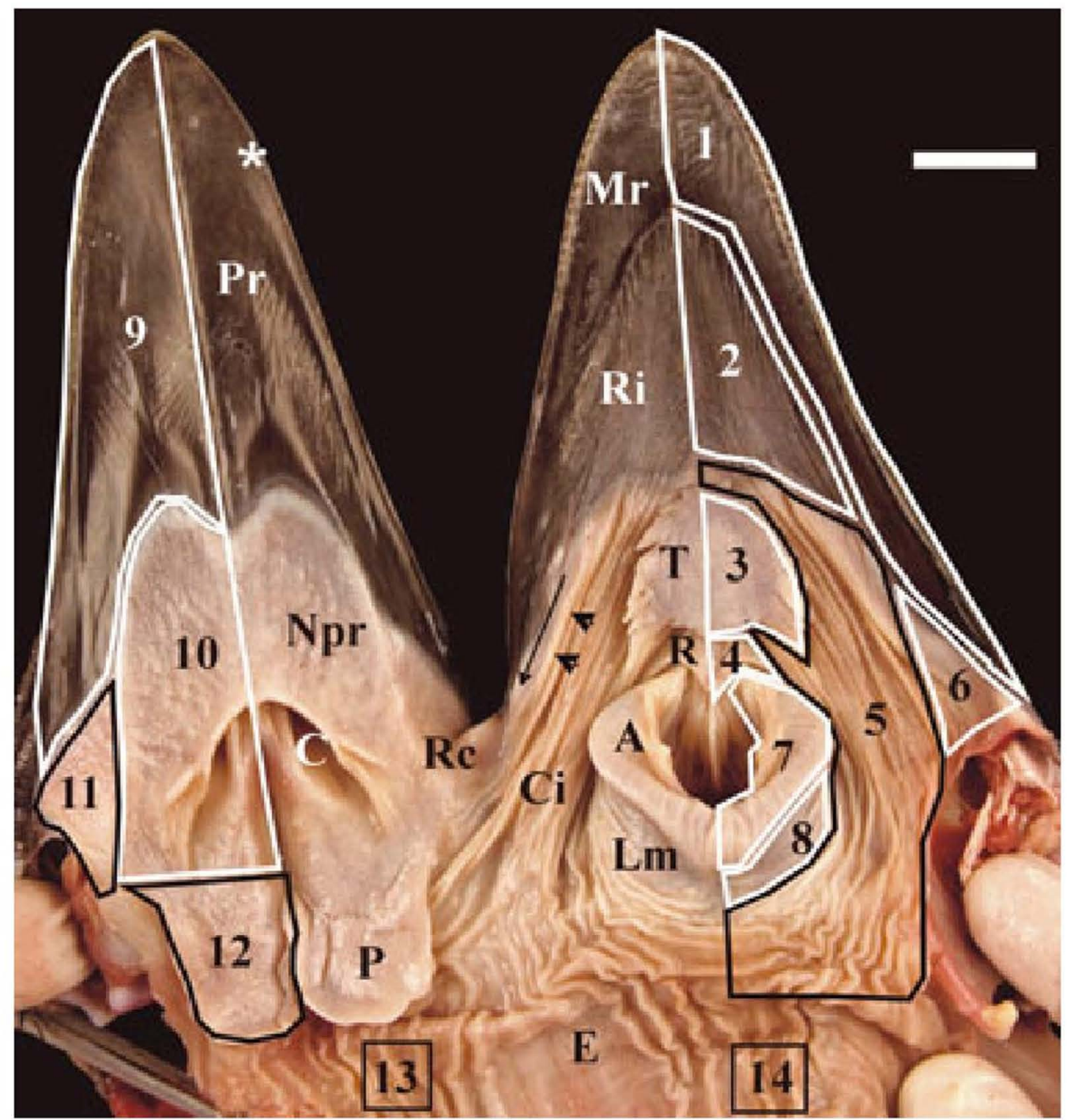

Fig. 1-Oropharynx and proximal esophagus of the emu openly displayed to show the salient features. The numbered zones of the right floor and roof represent the regions sampled for light microscopy. Within each outlined region transverse sections were excised at regular intervals of about $5 \mathrm{~mm}$. The esophagus was sampled in two regions only (13 and 14). The left side of the floor and the roof depict the most obvious gross morphological features. Mandibular rhamphotheca $(\mathrm{Mr})$, maxillary rhamphotheca $\left(^{\star}\right)$, rostral interramal region (Ri), caudal interramal region (Ci) with the large lateral fold (arrow) and the enclosed recess opening medially (arrowheads), tongue body ( $\mathrm{T}$ ), tongue root $(\mathrm{R})$, laryngeal mound $(\mathrm{Lm})$, arytenoid cartilage (A), pigmented roof $(\mathrm{Pr})$, non-pigmented roof $(\mathrm{Npr})$, rictus $(\mathrm{Rc})$, choana (C), pharyngeal fold $(\mathrm{P})$, proximal esophagus $(\mathrm{E})$. Bar $=2 \mathrm{~cm}$. 
overlying either simple tubular glands or simple branched tubular glands, or a combination of both gland types. The only non-pigmented, non-keratinised aglandular region was the caudal part of the laryngeal mound bordering the proximal esophagus.

Simple tubular glands. These glands were located exclusively on the frenulum of the tongue (forming the polystomatic frenular gland), the caudal interramal region (excluding the dorsal aspect of the large lateral fold) (the polystomatic medial mandibular gland) (Figs 1,2 and 4), the mucosa overlying the rostral half of the arytenoid cartilages and the rostro-lateral aspect of the cricoid cartilage of the laryngeal mound (polystomatic crico-arytenoid gland) (Fig. 1 and 2) and the proximal esophagus (forming the esophageal glands) (Figs 1, 2 and 3A) (Table 1). Additionally, they occurred together with simple branched tubular glands (see below) on the non-pigmented oropharyngeal roof (caudally), the rictus, the pharyngeal folds, the caudo-ventral tongue body and tongue root (Figs 1 and 2) (Table 1). In the pharyngeal folds of the oropharyngeal roof (Fig. 1), the simple tubular glands were most abundant in the tonsillar crypts where they were associated with diffuse lymphoid tissue, whereas the simple branched tubular glands were located beneath the ventral surface of the folds (Fig. 5C). In all other regions where both types of glands were present, the simple tubular glands occurred most often in groups or rows between the openings of the simple branched tubular glands. The esophageal glands were tightly packed and were separated only by occasional accumulations of diffuse lymphoid tissue (Fig. 3A). The openings of the simple tubular glands could not be observed macroscopically (compare to the simple branched tubular glands described below) or by stereomicroscopy. However in the three heads prepared with Indian ink these glands were clearly visible, using stereomicroscopy, as narrow, vertical black tubes extending from the surface to deep within the tissue. This technique whereby the lumen of the simple tubular glands was filled with black ink facilitated identification of the glands and also the extent of the glandular fields.

The simple tubular glands present in the oropharynx and proximal esophagus displayed similar morphological features. In most instances each gland constituted a single, tubular unit (Fig. 3B) although double and occasional triple branched forms were observed. Double branched glandular units displayed a higher frequency in the proximal esophagus than in the oropharynx. Although basically tubular in shape, some glandular units displayed a broader base, thus appearing more flask-shaped. The glands were lined by a simple columnar epithelium (Fig. 3C) which became low columnar in the neck of the gland traversing the stratified squamous surface epithelium (Fig. 3B). The PAS-positive (Fig. 3A), mucus-secreting cells displayed a dark, basally-positioned, flattened nucleus within a lightly basophilic cytoplasm (Fig. 3C). The apical region of some of the cells was filled with a very fine, strongly basophilic granular material, which was present in the lumen of some glands (Fig. 3B) and also extended onto the mucosal surface. There was no noticeable cycle of secretory activity and the mucus-secreting cells appeared similar in all sections examined. The base of the glands extended for only a short distance into the dense irregular connective tissue below the epithelium (Figs 3A,B and 4) and opened onto the surface via a duct lined by cells similar in appearance to those forming the secretory part of the gland. The simple tubular glands were thus partly intraepithelial in nature (Figs 3A,B and 4).

Simple branched tubular glands. These glands were located exclusively in the tongue body dorsum and rostral ventrum (forming the polystomatic dorsal and rostro-ventral lingual glands, respectively) (Figs 1 and 2), the dorsal aspect of the large bi-lateral folds of the caudal interramal region (polystomatic lateral mandibular glands) (Figs 1,2 and 4) and the more rostral portion of the caudal non-pigmented roof (Figs 1, 2, and 3D) (Table 1). Additionally, they occurred together with simple tubular glands in the roof of the oropharynx (including the pharyngeal folds), maxillary and mandibular rictus, caudo-ventral tongue body and the tongue root (Figs 1 and 2) (Table 1). The simple branched tubular mucus-secreting glands were situated deeper within the connective tissue than the simple tubular glands. Each simple branched tubular gland formed a large glandular unit that was macroscopically visible beneath the surface of the oropharynx as a pale doughnut-shaped structure. The ring of the doughnut represented the collection of individual tube-shaped secretory units, while the dark spot in the middle reflected the central lumen into which the individual secretory units opened, and the duct opening. The size and distribution of the duct openings was more obvious after Indian ink treatment and a clear distinction between these glands and the smaller simple tubular glands was obtained. This method also further confirmed the distribution of the simple branched tubular glands.

Viewed at low magnification, the simple branched tubular glands presented oblong (Figs 3D and 5C), round (Figs 4 and $5 \mathrm{~A}$ ), oval or pear-shaped profiles. The glands were housed in the sub-epithelial dense irregular connective tissue, the depth of which varied depending on the part of the oropharynx in which it was located. In the rostral part of the non-pigmented roof and the rictus, for example, the connective tissue layer was relatively thin, whereas in the mid-dorsal and ventral tongue body, and in the pharyngeal folds, it formed a deep layer. The gland profiles mentioned above appeared to be influenced by the depth of the connective tissue in which they were housed, as well as by the relative density of the glands. The glands tended to assume a more round profile (Figs 4 and $5 \mathrm{~A}$ ) in regions with a 


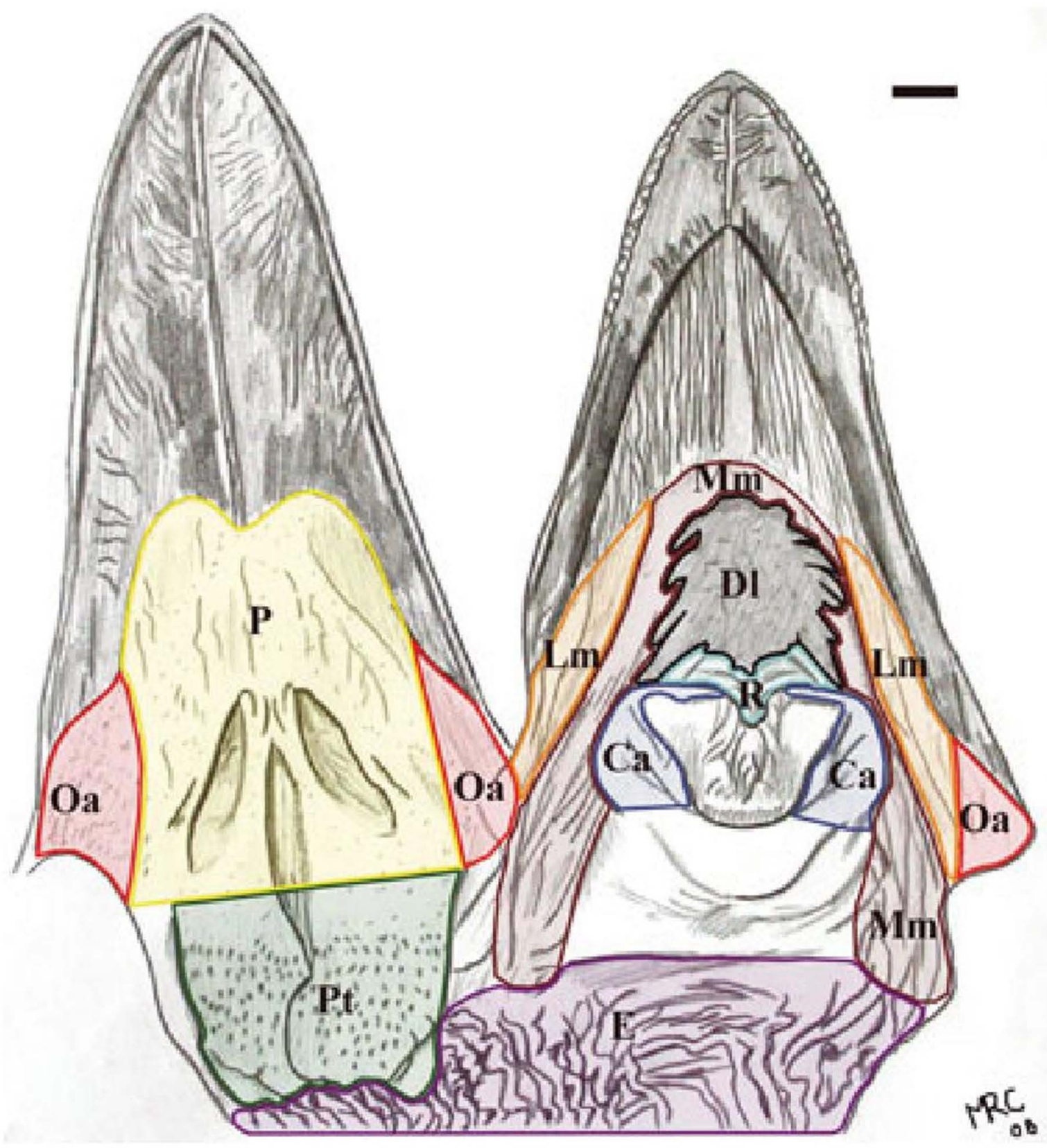

Fig. 2 - Schematic representation of the mucus-secreting glandular fields identified in the oropharynx and proximal esophagus of the emu: palatine ( $\mathrm{P}$, yellow), oral angular $(\mathrm{Oa}, \mathrm{red})$, pharyngeal tonsillar, ( $\mathrm{Pt}$, green), lateral mandibular ( $\mathrm{Lm}$, orange), medial mandibular ( $\mathrm{Mm}$, brown), dorsal lingual (Dl, black), radical ( $\mathrm{R}$, light blue), cricoarytenoid (Ca, dark blue) and esophageal (E, purple) glands. Bar $=1 \mathrm{~cm}$. 
lower density of glands and a thinner connective tissue layer and became larger and more oblong in more densely packed regions and where the connective tissue extended deeper below the epithelium (Fig. 5C). Thus the smallest glands were situated in the shallow connective tissue layer of the rostral non-pigmented roof and the largest glands occurred in the midline of the dorsal and ventral tongue body and the caudal free part of the pharyngeal folds where a deep zone of connective tissue was apparent (Fig. 5C). Each gland was encapsulated by a condensed layer of the connective tissue immediately surrounding the gland, resulting in the formation of distinct glandular units (Fig. 3D). This layer varied in width depending on the density of the glands and the relative amount of surrounding connective tissue. Thus less densely packed glands were encapsulated by a wide, ill-defined connective tissue layer, whereas in areas with a higher gland density the layer was narrow and compacted (Fig. 3D). Numerous fine septa radiated from the containing fibrous layer to separate the individual tubular secretory units. The septa distributed a rich capillary supply between the units (Fig. 5B).

Viewed at higher magnification the simple branched tubular glands were composed of numerous simple tubular secretory units which emptied into a large central lumen (Fig. $5 A, B$ ) and which in some glands was clearly lined by a pseudostratified ciliated columnar (Fig. 5D) or simple ciliated columnar epithelium. The cells forming the secretory units displayed similar features to the cells lining the simple tubular glands and demonstrated a PAS-positive staining reaction (Fig. 3D) thus confirming the secretion of mucopolysaccharides. The cells lining the tubular units showed varying degrees of secretory activity. Active secretory units were characterized by cells displaying basally-positioned round vesicular, or dark, flattened nuclei, and ample apical cytoplasm filled with lightly basophilic granular material. Inactive units displayed cuboidal cells containing a round central nucleus and relatively less and darker staining cytoplasm than that of active cells. Accumulations of mucus were often visible in the lumen of the secretory units and the large central lumen (Figs 3D and 5B), depending on the activity of the gland. The central lumen narrowed as it passed through the epithelium, forming the secretory duct (Fig. 5A) which communicated with the oropharynx. This duct was lined by a single layer of vertically oriented squamous cells continuous with the surface layer of the epithelium although in some instances a ciliated columnar epithelium was observed along part of the duct. Glands with ciliated ducts were most commonly observed in the tongue body ventrum and pharyngeal folds. Ciliation did, however, occur in the other glands, but less frequently.

In some instances variably sized Herbst corpuscles were closely aligned with the connective tissue capsule of the simple branched tubular glands (Fig. 5B), although isolated corpuscles also appeared independently in the surrounding connective tissue (Fig. 3D). Masses of diffuse and nodular lymphoid tissue were also associated with the glands, often stretching from the periphery of the glandular unit to the lumen and distorting the structure of the glands. This phenomenon was particularly obvious in the pharyngeal folds (Fig. 5C).

\section{Discussion}

\section{Distribution and glandular fields}

As noted in many other avian species, glandular tissue was a major component of the non-pigmented regions (except for the tongue which was variably pigmented) of the emu oropharynx and was located in the connective tissue of the regions and sub-regions listed in Table 1. Glands are reportedly best developed in birds with a dry diet, such as seed or insect eaters (King and McLelland 1984). The emu has a varied diet which includes seeds and insects (Davies 1978) and the oropharynx and proximal esophagus of this species therefore also displays a high density of mucussecreting glands. Although not described in detail, it would appear that glandular tissue is abundant in the oropharynx of the greater rhea (Feder 1972) and ostrich (Porchescu 2007; Tivane 2008) and has a similar distribution to that of the emu.

In birds, definitive salivary glands do not occur; instead they are replaced by collections of large numbers of simple and branched tubular mucus-secreting glands lined by large mucous cells (Banks 1993). Thus the salivary glands of birds are mostly a collection of independent glandular units that form a glandular field or polystomatic gland (Fahrenholz 1937). This situation is evident in the emu as well as in the greater rhea (Feder 1972) and ostrich (Tivane 2008). The nomenclature used to describe the grouping of avian salivary glands has been found in the past to be both inconsistent, confusing (Ziswiler and Farner 1972) and conflicting (McLeod 1939). This is partly due to the fact that in birds the regions of glandular tissue tend to merge with one another (Tucker 1958). Fahrenholz (1937), in a review of the older literature, grouped the oropharyngeal glands of birds into: mandibular, lingual and cricoarytenoid glands in the floor, and maxillary, palatine, oral angular and sphenopterygoid glands in the roof. In a review of vertebrate salivary glands, Tucker (1958) lists the following in birds: the oral angular glands (often rudimentary), the palatine group (palatine, median, lateral, anterior, posterior, internal and external glands), the intermandibular group (anterior, posterior, external posterior and inferior posterior glands) and the pharyngo-esophageal group (pterygoi-dal-palatine, cricoarythenoidal and esophageal glands). In the chicken monostomatic maxillary oral angular 

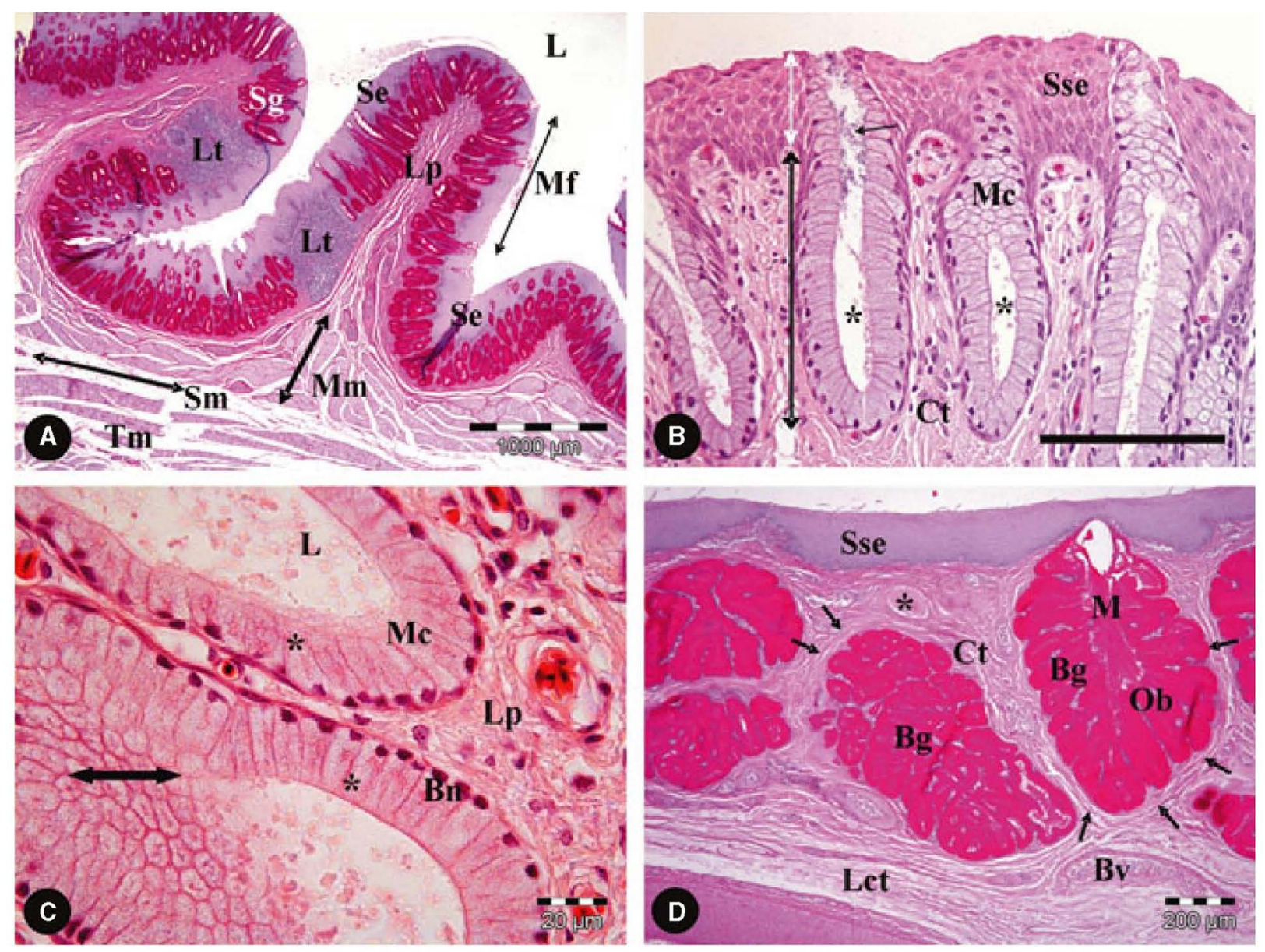

Fig. 3 A. PAS-positive staining reaction of the simple tubular mucus-secreting glands $(\mathrm{Sg})$ in the proximal esophagus (esophageal glands). Aggregations of lymphoid tissue (Lt) lie between the glands. Lumen (L), mucosal fold (Mf), Muscularis mucosae (Mm), submucosa (Sm), Tumica muscularis (Tm), stratified squamous epithelium (Se). - B. Simple tubular mucus-secreting glands of the caudal interramal region forming the medial mandibular gland. Note the tubular lumen $\left(^{\star}\right)$ of the glands containing fine basophilic granular material (arrow). Columnar mucus-secreting cells (Mc) line most of the gland (black double-headed arrow) whereas the cells lining the part of the gland traversing the stratified squamous epithelium (Sse) (white double-headed arrow) display a gradual decrease in height, becoming low columnar. Connective tissue (Ct).

Bar $=100 \mu \mathrm{m}$. - C. High magnification of the simple columnar mucus-secreting cells (Mc) which form the simple tubular esophageal glands. Note the typical features, basal nuclei $(\mathrm{Bn})$ and basophilic foamy cytoplasm $\left.{ }^{\star}\right)$, of the mucus-secreting cells. Lumen (L), Lamina propria $(\mathrm{Lp})$, cross section of the apical part of the cells (double-headed arrow). - D. Glandular region of the non-pigmented oropharyngeal roof (palatine gland) lined by a non-keratinised stratified squamous epithelium (Sse), showing the PAS-positive staining reaction of the large, simple branched tubular glands $(\mathrm{Bg})$ of which one displays an oblong profile $(\mathrm{Ob})$. Note how the irregular dense connective tissue (Ct) houses the glands, forming slightly condensed, concentric enveloping layers (arrows). A Herbst corpuscle $\left({ }^{\star}\right)$ is present and the deeper, more loosely arranged connective tissue (Lct) contains large blood vessels (Bv). 
glands and polystomatic palatine (medial and lateral), sphenopterygoid, posterior submandibular (medial, internal and lateral), cricoarytenoid and anterior and posterior lingual glands were identified (Saito 1965). The anatomical regions of the emu oropharynx have been clearly defined (Crole and Soley 2010a) and are depicted in Fig. 1. As the glands observed in the emu oropharynx showed no definitive, delineated groupings, the glandular fields were named according to the previously described anatomical regions and sub-regions of the oropharynx (Fig. 1) (Table 1) as detailed below.

Naming of glandular fields. In the emu three glandular fields were recognized on both the roof (palatine, oral angular and pharyngeal tonsillar) and floor (mandibular, lingual and crico-arytenoid) of the oropharynx (see Fig. 2 and Table 1). In contrast, the glands identified in the greater rhea (Feder 1972) and ostrich (Tivane 2008) oropharynx have not been named. The palatine glands of most birds (see reviews by Fahrenholz 1937 and McLelland 1979; Saito 1965; Warner et al. 1967; Samar et al 1999) are divided into left and right groups (each of which are further subdivided into lateral and medial groups) by the rostral part of the choana. However, the polystomatic palatine gland of the emu forms a single, diffuse glandular field that occupies the non-pigmented part of the roof bordered by the pigmented roof, rictus and pharyngeal folds (see Fig. 1).

The sphenopterygoid glands reported in birds (see reviews by Fahrenholz 1937 and McLelland 1979; Saito 1965; Warner et al 1967), and which have also been referred to as tonsillar glands (see Fahrenholz 1937), appear to occupy the region corresponding to the pharyngeal folds in the emu. The pharyngeal folds in this species are large, well-defined structures (Crole and Soley 2010a), containing a high density of lymphoid tissue (present study). Thus the naming of this polystomatic gland the pharyngeal tonsillar gland, is more descriptive for this species than sphenopterygoid glands.

Glandular tissue occurs in the angle of the mouth (Rictus) of most birds, and has been referred to as the oral angular gland (see reviews by Fahrenholz 1937 and McLelland 1979; Saito 1965; Warner et al 1967). Although this gland is generally monostomatic (see reviews by Fahrenholz 1937 and McLelland 1979) polystomatic fields have been reported in some species (Antony 1920), a situation also apparent in the emu.

A monostomatic maxillary gland has been reported in numerous avian species (see reviews by Fahrenholz 1937 and McLelland 1979; Saito 1965; Warner et al 1967) in a region which appears to coincide with the pigmented oropharyngeal roof of the emu. This region is aglandular in the emu and this species has no maxillary gland.

The mandibular gland in birds shows a diversity in size, grouping and function (see reviews by Fahrenholz 1937 and McLelland 1979), and is classically divided into anterior (rostral) and posterior (caudal) groups. The mandibular gland of the emu corresponds to the caudal mandibular glands reported in other birds (see reviews by Fahrenholz 1937 and McLelland 1979; Saito 1965; Warner et al 1967) and is divided into lateral and medial groups. Unlike the spatially separated mandibular glands reported for other birds (see review by Fahrenholz 1937), the mandibular glands of the emu are continuous with one another and defined by the anatomical region and type of glands present. The lateral mandibular gland occupied the dorsal surface of the large lateral folds in the caudal interramal region. The medial mandibular gland essentially occupied the remainder of the interramal region and diverged laterally around the laryngeal mound, merging caudally with the esophageal glands.

There is little conformity in the literature regarding the naming of lingual glands in birds, with many of the papers describing their location using human directional terminology (e.g. Antony 1920; Fahrenholz 1937; Tucker 1958; Warner et al. 1967; Ziswiler and Farner 1972). The situation is further complicated by inconsistency in the anatomical description of the various parts of the tongue (see Crole and Soley 2009b). Some birds reportedly have no lingual glands whereas in other species lingual glands are the only glands found in the entire oropharynx (see review by Fahrenholz 1937). Based on a previous study (Crole and Soley 2009c) the glands of the emu tongue are divided into dorsal, rostro-ventral and caudo-ventral (tongue body), radical (tongue root) as well as frenular (situated on the frenulum) glands. Three groups of glands have been identified on the ostrich tongue, namely, dorsal, ventral and tongue-root lingual glands (Jackowiak and Ludwig 2008). The presence of frenular glands has not previously been noted in birds (Tucker 1958), although in the emu this structure was well supplied with simple tubular glands (Crole and Soley 2009c; present study). Although a radical gland (the tongue root is an obvious anatomical feature in the emu) has not been named as such in the avian literature, this gland seems to have been incorporated in descriptions of the crico-arytenoid gland (see below). However some authors distinguish a "radical gland" separate from the cricoarytenoid gland and it would appear that terms such as posterior lingual gland (Warner et al. 1967; Hodges 1974; Nickel et al. 1977), pre-glottal glands (Liman et al. 2001) and tongue-root glands (Jackowiak and Ludwig 2008) are used synonymously for this particular glandular field.

The crico-arytenoid gland in birds occurs in the vicinity of the larynx (Fahrenholz 1937). From the review of the earlier literature by Fahrenholz (1937) it is apparent that some authors include the glandular tissue situated between the tongue and the larynx as part of this gland; this is also evident in the chicken (Saito 1965). In the emu the glandular tissue between the tongue and laryngeal mound is termed the radical gland (see above) and only the 


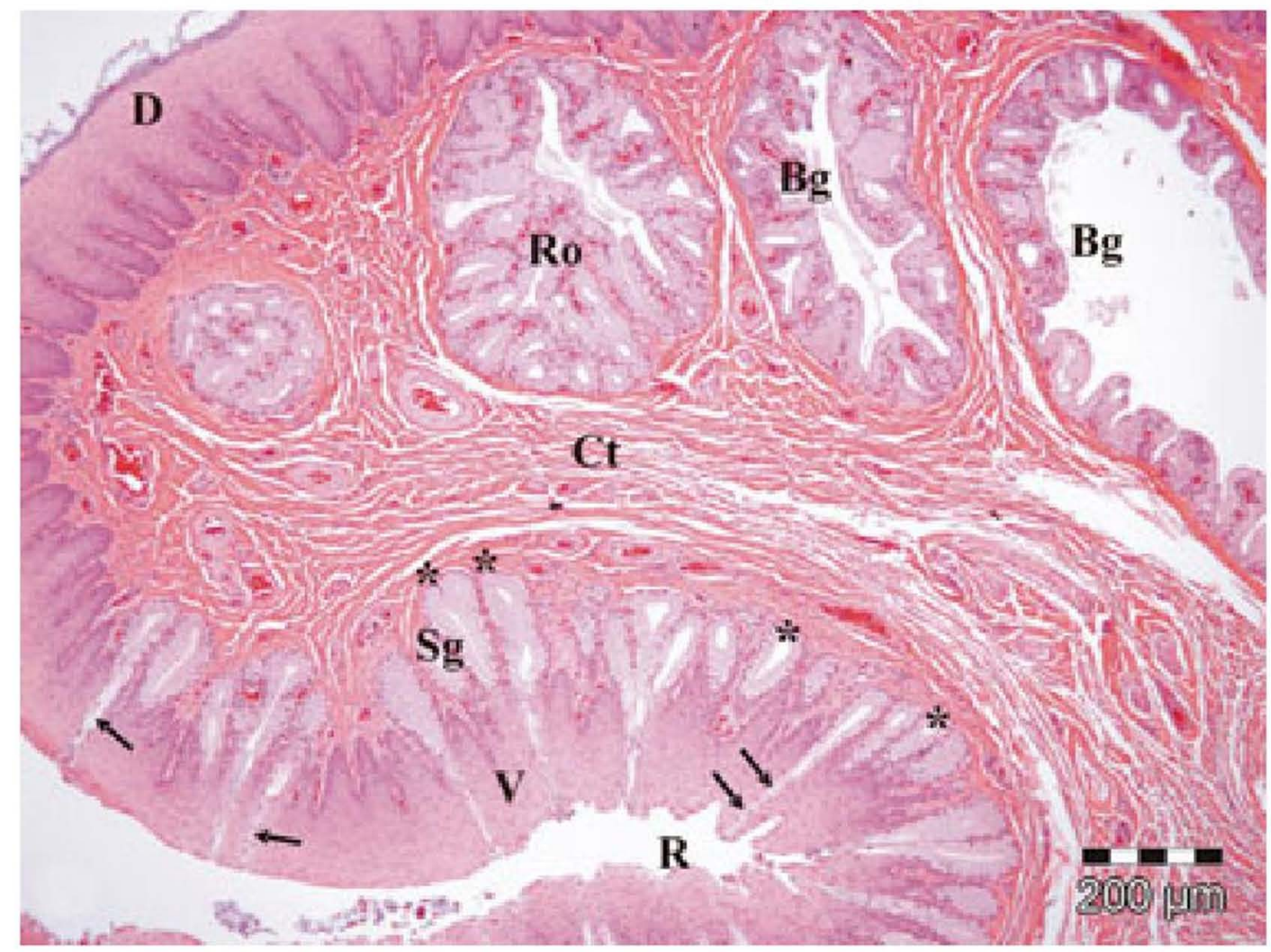

Fig. 4-The large lateral fold in the caudal interramal region (see Fig. 1) showing the large, simple branched tubular glands ( $\mathrm{Bg})$ restricted to the dorsal (D) surface with simple tubular glands ( $\mathrm{Sg}$ ) present on the ventral $(\mathrm{V})$ surface and opening to the medial-facing groove or recess $(\mathrm{R})$. Note the limited penetration $\left(^{\star}\right)$ of the simple tubular glands into the underlying connective tissue $(\mathrm{Ct})$ and the mucus-secreting cells lining the duct (arrows). The simple branched tubular glands are situated deeper within the connective tissue than the simple tubular glands and show a decrease in size towards the tip of the fold. Round profile of a simple branched tubular gland (Ro). 

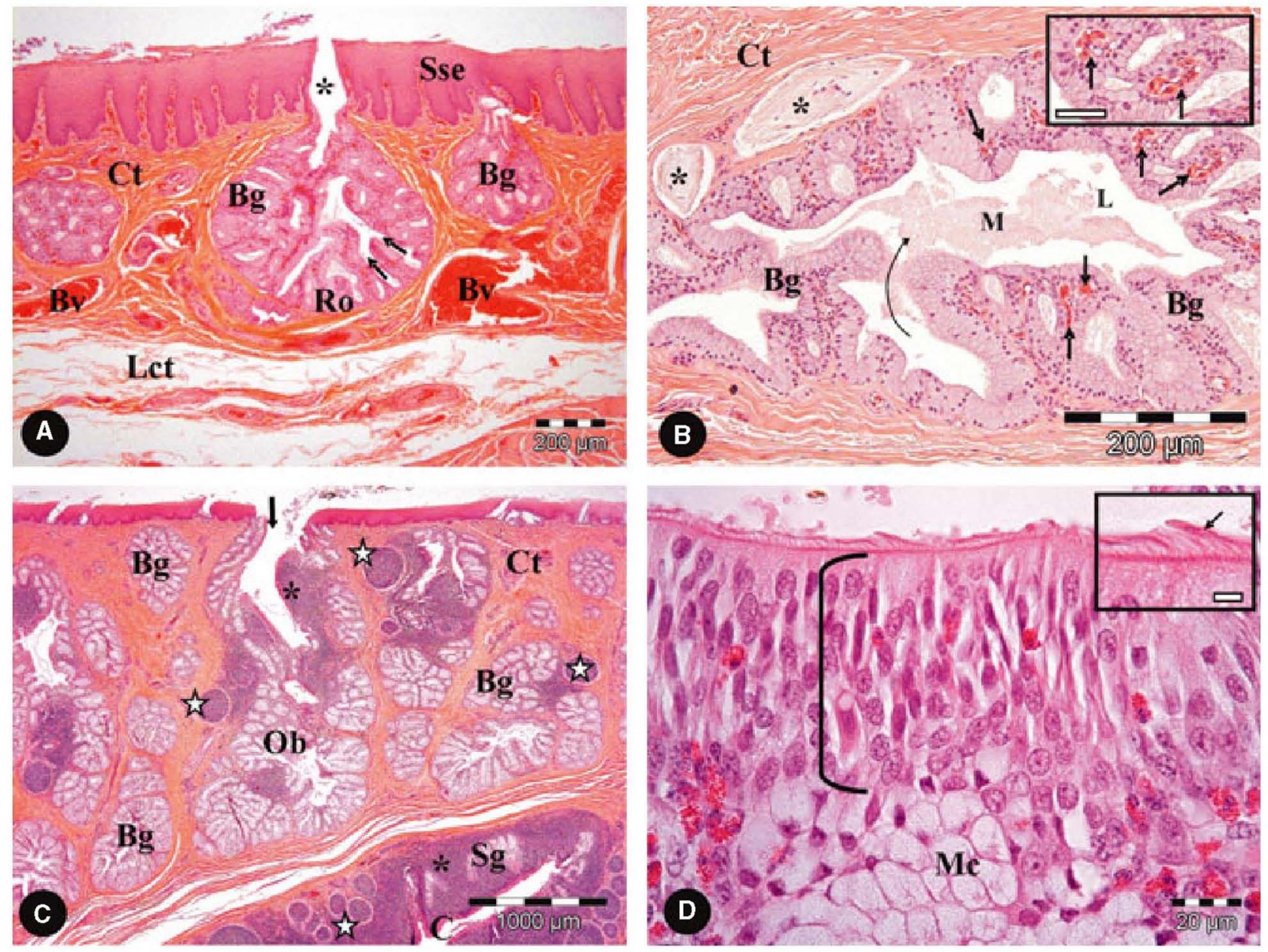

Fig. 5 - A. Section through the mucosa of the maxillary rictus (oral angular gland). Large, simple branched tubular glands (Bg) are present in the irregular dense connective tissue (Ct). Loose connective tissue (Lct), large blood vessels (Bv), gland opening ( ${ }^{\star}$ ), stratified squamous epithelium (Sse), round profile of a simple branched tubular gland (Ro, openings of individual secretory units (arrows)). - B. A large simple branched tubular gland $(\mathrm{Bg})$ with associated Herbst corpuscles $\left(^{\star}\right)$ in the connective tissue $(\mathrm{Ct})$ of the mandibular rictus (oral angular gland). Note the large lumen (L) filled with pale basophilic material (mucus) $(M)$ and the rich capillary supply between the secretory units (arrows) (inset). Note the connection between the individual tubular secretory units and the central lumen (curved arrow). Inset bar $=40 \mu \mathrm{m}$. $-\mathrm{C}$. Ventral surface of the pharyngeal fold (pharyngeal tonsilar gland) displaying numerous, large, simple branched tubular glands $(\mathrm{Bg})$ and associated lymphoid tissue in the dense irregular connective tissue (Ct). The lymphoid tissue consists of diffuse $\left({ }^{\star}\right)$ and nodular (white star) accumulations. Note the large gland opening to the surface (arrow). Simple tubular glands (Sg) are also present in the tonsillar crypts (C). Oblong-shaped gland (Ob). - D.

Psuedostratified ciliated columnar epithelium (bracket) lining the lumen of a large, simple branched tubular mucus-secreting gland in the pharyngeal fold. The inset shows the cilia (arrow) on the epithelial surface at higher magnification (bar $=4 \mu \mathrm{m}$ ). Mucous cells $(\mathrm{Mc})$. 
glandular tissue situated in the mucosa covering the rostral half of the cricoid as well as the arytenoid cartilages constitutes the polystomatic crico-arytenoid gland.

\section{Structure}

Oropharynx. Two types of salivary glands were evident in the emu, namely, small, simple tubular mucus-secreting glands (single and branched) and large, simple branched tubular mucus-secreting glands, both similar to those noted in the ostrich (Tivane 2008). The glands in the greater rhea were described as being tubulo-alveolar with typical mucus-secretory features (Feder 1972) with no further mention of size or detail of their structure.

Tubular glands are the most common type found in birds (Fahrenholz 1937; Ziswiler and Farner 1972) with the alveolar type being the exception (Fahrenholz 1937). Serous elements are normally absent (Ziswiler and Farner 1972), a feature also apparent in the ratites. Serous cells have, however, been identified to form part of the salivary glands of the quail, where they stained negative for PAS (Warner et al. 1967). No serous cells were identified in the emu salivary glands and all cells stained PAS-positive. Based on structural characteristics, all the glands in the various ratite species studied (emu (present study), ostrich (Jackowiak and Ludwig 2008; Tivane 2008) and greater rhea (Feder 1972)), were exclusively mucus-secreting. Hodges (1974) and McLelland (1979) state that the salivary glands of the oral and pharyngeal cavities in birds are compound tubular structures. Although large, the branched tubular glands seen in the emu did not reveal a complex duct system and were therefore not compound in nature. The tubular secretory units simply opened into a central lumen communicating with the surface via a wide duct. The salivary glands depicted for various birds have been classified as simple branched tubular, tubulo-alveolar and alveolar mucus-secreting glands (Calhoun 1954; Warner et al. 1967; Hodges 1974; McLelland 1975, 1979; Samar et al. 1999) although they appear morphologically similar to the glands identified as simple branched tubular in the emu oropharynx and proximal esophagus.

The simple branched tubular glands in the emu manifested macroscopically as doughnut-shaped structures with a small central spot or depression which represented the duct opening (Crole and Soley 2009b,c, 2010a). The openings of the salivary glands of many birds (Gardner 1927), as well as the chicken (King and McLelland 1984) and ostrich (Tivane 2008) are also seen as small openings macroscopically.

The lumen of some of the large, simple branched tubular glands, particularly those in the pharyngeal folds, in the emu displayed a pseudostratified ciliated columnar epithelium, presumably to assist in extrusion of mucus from the glands. The mucus secretions of the simple branched oropharyngeal glands apparently accumulate in the large lumen below the epithelium and move to the surface through short ducts. Thus extrusion of viscid secretion may be due to the action of cilia, where present, as well as through pressure build-up of accumulated secretions. The large openings would offer little resistance to the passage of the secretions. Hodges (1974) notes that the presence of smooth muscle fibres around glands is disputed in birds. The simple branched tubular glands in the emu are surrounded by a well-defined connective tissue capsule with no evidence of smooth muscle (with the staining techniques used), a finding similar to that in the ostrich (Tivane 2008). Connective tissue capsules around glands in other birds have also been noted (Warner et al. 1967; Hodges 1974). However, in the quail (Warner et al. 1967) smooth muscle fibres were identified surrounding the glands in the oropharynx.

Proximal esophagus. A prominent feature of the avian esophagus is the presence of numerous simple tubular mucussecreting glands, a feature also noted in the ostrich (Tivane 2008) and greater rhea (Feder 1972). In the emu, the esophageal glands are situated in the Lamina propria (Herd 1985) (although much of their length is enclosed in the epithelial lining) (present study) into which they extend for only a short distance, a feature similar to that in the ostrich (Porchescu 2007; Tivane 2008) and greater rhea (Feder 1972). This is in contrast to mammals where glands are situated in the submucosa (Ross and Pawlina 2006). In birds the esophageal glands are noted to lie in the Tunica mucosae (Ziswiler and Farner 1972) or more specifically, the Lamina propria (McLelland 1975). In the emu the glands are simple tubular, sometimes branched and mucus-secreting (PAS-positive) in nature. In contrast esophageal glands of other birds have been reported to range from tubular to alveolar (Ziswiler and Farner 1972), mainly alveolar with some branching (Warner et al. 1967) or branched (Koch 1973). In the emu the simple tubular esophageal glands were structurally similar to the oropharyngeal glands.

\section{Function}

During feeding in ratites (Bonga Tomlinson 2000; Gussekloo and Bout 2005) food is held between the bill-tips and then accelerated through the oropharynx where it comes to land in the proximal esophagus prior to swallowing. Here it is covered by the gland-rich ventral surface of the pharyngeal folds and would conceivably be coated by large amounts of mucus emanating from the exceptionally large, simple branched tubular glands present on the ventral 
Table 1 Glandular fields of the emu oropharynx and proximal esophagus

\begin{tabular}{|c|c|c|c|}
\hline Anatomical region & Anatomical sub-region ${ }^{1}$ & Name of glandular field (polystomatic gland) & Type of secretory units forming glandular field \\
\hline \multirow[t]{3}{*}{ Oropharyngeal roof } & $\begin{array}{l}\text { Non-pigmented roof (from } \\
\text { cranial to base of the } \\
\text { choana) }\end{array}$ & Palatine gland (GI. palatina) & $\begin{array}{l}\text { Mainly simple branched tubular and a few simple } \\
\text { tubular }\end{array}$ \\
\hline & Rictus & Oral angular gland (GI. anguli oris) & Simple branched tubular and simple tubular \\
\hline & Pharyngeal folds & Pharyngeal tonsillar gland (Gl. tonsilla pharyngea) ${ }^{*}$ & $\begin{array}{l}\text { Very large, simple branched tubular, simple } \\
\text { branched tubular and simple tubular }\end{array}$ \\
\hline \multirow[t]{10}{*}{ Oropharyngeal floor } & Caudal interramal region & Mandibular glands (Gll. mandibulares) ${ }^{*}$ & \\
\hline & & - Lateral mandibular gland (GI. mandibularis lateralis) & $\begin{array}{l}\text { Simple branched tubular (dorsally in the large } \\
\text { fold) }\end{array}$ \\
\hline & & - Medial mandibular gland (GI. mandibularis medialis)" & Simple tubular (medial to the large fold) \\
\hline & Tongue body ${ }^{2}$ & Lingual glands (Gll. linguales) & Simple branched tubular and simple tubular \\
\hline & & - Dorsal lingual gland (Gl. lingualis dorsalis) & - Simple branched tubular \\
\hline & & - Rostro-ventral lingual gland (GI. lingualis rostro-ventralis) ${ }^{*}$ & - Simple branched tubular \\
\hline & & - Caudo-ventral lingual gland (Gl lingualis caudo-ventralis) ${ }^{*}$ & - Simple branched tubular and simple tubular \\
\hline & Tongue $\operatorname{root}^{2}$ & - Radical gland (Gl. radix linguae) ${ }^{*}$ & - Simple branched tubular and simple tubular \\
\hline & Frenulum $^{2}$ & - Frenular gland (Gl. frenulum linguae) & - Simple tubular \\
\hline & Laryngeal mound & Crico-arytenoid gland (GI. cricoarytenoidea) & Simple tubular \\
\hline Esophagus & Proximal esophagus & Esophageal glands (Gll. esophageales) & Simple tubular \\
\hline
\end{tabular}

"Based on, but not specifically named in Nomina Anatomica Avium (McLelland 1993).

${ }^{1}$ Crole and Soley 2010a.

${ }^{2}$ Crole and Soley $2009 \mathrm{c}$. 
surface of the folds. During the swallowing phase in ratites the dorsal surface of the tongue scrapes against the roof of the oropharynx, as the tongue retracts caudally (Bonga Tomlinson 2000). In the emu this process removes any food particles that may have stuck to the roof during the passage of food through the oropharynx (see Crole and Soley 2009c). It is clear that the surfaces in the emu most exposed to friction during this process would be the dorsal surface of the tongue, the non-pigmented roof and the pharyngeal folds. As these surfaces are non-keratinised, they are protected by copious secretions from the underlying glands (see below). In these regions exposed to higher friction, the main gland found was of the simple branched tubular type (Table 1). These glands, despite a larger intervening space between gland openings, would conceivably secrete a higher volume of mucous than a field of simple tubular glands with a higher density of openings (seen by stereomicroscopy after treatment with Indian ink). In regions exposed to less friction (caudal interramal region and ventral tongue body) a field of mainly simple tubular glands is present. The proximal esophagus contains a high density of simple tubular glands, which would provide a continuous layer of mucus on the esophageal mucosa to assist in the transport of the already partially lubricated (from the pharyngeal folds) food bolus. It would appear that in the emu the type of glands composing a glandular field correspond directly to the amount of friction experienced by the mucosa during feeding, which in turn translates to the particular feeding method employed by ratites.

The main function of the salivary glands in birds is muco-genesis to form saliva (Ziswiler and Farner 1972) which provides moisture and lubrication for food boli (Ziswiler and Farner 1972; Nickel et al. 1977; King and McLelland 1984; Gargiulo et al. 1991; Liman et al I. 2001). Mucins are visco-elastic organic components of mucus formed by high molecular weight glycoproteins and coat all mucosal surfaces (Tabak et al. 1982). They provide protection from desiccation and mechanical damage, help maintain cellular water balance, provide lubrication and are antimicrobial in action (Tabak et al. 1982). Sticky saliva also assists in the backward propulsion of food and prevents regurgitation (McLelland 1990). All these functions would be fulfilled by the mucus-secreting glands in the emu oropharynx. Thus the non-keratinised epithelia of the emu oropharynx are protected by the mucus secretions of the numerous underlying glands.

\section{Acknowledgements}

The authors thank Mr. Peter Duncan (Krugersdorp, Gauteng Province, South Africa) and Mrs. Petra Rough (Rustenburg, North-West Province, South Africa) for providing the emu heads; Dr. Fritz Huchzermeyer for translation of German texts; the support staff of the Department of Anatomy and Physiology, Faculty of Veterinary Science, University of Pretoria, for general assistance; and the University of Pretoria, South Africa for financial support.

\section{References}

Al-Mansour, M.I. and Jarrar, B.M. 2004. Structure and secretions of the lingual salivary glands of the white-cheeked bulbul, Pycnonotus leucogenys (Pycnontidae). -Saudi Journal of Biological Sciences 11: 119-126.

Antony, M. 1920, Über die Speicheldrüsen der Vögel. -Zoologische Jahrbuecher Abteilung fuer Anatomie und Ontogenie der Tiere 41: 547-660.

Banks, W.J. 1993. Comparative organology. In Reinhardt, R.W. (Ed): Applied Veterinary Histology, pp. $356-360$.

Mosby-Year Book, Inc, St. Louis.

Baumel, J.J., King, A.S., Breazile, J.E., Evans, H.E. and Vanden Berge, J.C. 1993. Handbook of Avian Anatomy:

Nomina Anatomica Avium, 2nd edn. Nuttall Ornithological Club, Cambridge, Massachusetts, 779 p.

Bonga Tomlinson, C.A. 2000. Feeding in paleognathus birds. In Schwenk, K. (ed): Feeding: Form, Function, and Evolution in Tetrapod Vertebrates, pp. 359-394. Academic Press, San Diego.

Calhoun, M.L. 1954. Microscopic Anatomy of the Digestive System of the Chicken. Iowa State College Press, Ames, Iowa, $108 \mathrm{p}$.

Crole, M.R. and Soley, J.T. 2009a. Gland structure in the oropharynx and proximal oesophagus of the emu (Dromaius novaehollandiae). - Proceedings of the Microscopy Society of Southern Africa 39: 25.

Crole, M.R. and Soley, J.T. 2009b. Morphology of the tongue of the emu (Dromaius novaehollandiae). I. Gross anatomical features and topography. -Onderstepoort Journal of Veterinary Research 76: 335- 345.

Crole, M.R. and Soley, J.T. 2009c. Morphology of the tongue of the emu (Dromaius novaehollandiae). II. Histological features. Onderstepoort Journal of Veterinary Research 76: 347-361.

Crole, M.R. and Soley, J.T. 2010a. Gross morphology of the intra-oral rhamphotheca, oropharynx and proximal esophagus of the emu (Dromaius novaehollandiae). -Anatomia Histologia Embryologia 39: 207-218.

Crole, M.R. and Soley, J.T. 2010b. Surface morphology of the emu (Dromaius novaehollandiae) turgue. Anatomia Histologia Embryologia 39: in press.

Davies, S.J.J.F. 1978. The food of emus. -Australian Journal of Ecology 3: 411-422. 
Fahrenholz, C. 1937. Drüsen der Mundhöle. In Bolk, L., Göppert, E., Kallius, E. and Lubosch, W. (Eds): Handbuch der vergleichenden Anatomie der Wirbeltiere, pp. 115-206. Urban and Schwarzenberg, Berlin.

Feder, F.-H. 1972. Zur mikroskopischen Anatomie des Verdauung-sapparates beim Nandu (Rhea americana). Anatomischer Anzeiger 132: 250-265.

Gardner, L.L. 1927. On the tongue in birds. -The Ibis 3: 185-196.

Gargiulo, A.M., Lorvik, S., Ceccarelli, P. and Pedini, V. 1991. Histological and histochemical studies on the chicken lingual glands. - British Poultry Science 32: 693-702.

Gussekloo, S.W.S. and Bout, G.R. 2005. The kinematics of feeding and drinking in palaeognathous birds in relation to cranial morphology. - Journal of Experimental Biology 208: 3395-3407.

Herd, R.M. 1985. Anatomy and histology of the gut of the emu Dromaius novaehollandiae. -Emu 85: 43-46.

Hodges, R.D. 1974. The digestive system. In: The Histology of the Fowl, pp. 35-112. Academic Press, London.

Jackowiak, H. and Godynicki, S. 2005. Light and scanning electron microscopic study of the tongue in the white tailed eagle (Haliaeetus albicilla, Accipitiridae, Aves). -Annals of Anatomy 187: 251-259.

Jackowiak, H. and Ludwig, M. 2008. Light and scanning electron microscopic study of the structure of the ostrich (Strutio camelus) tongue. -Zoological Science 25: 188-194.

King, A.S. and McLelland, J. 1984. Digestive system. In Birds - Their Structure and Function, 2nd edn. pp. 84-109.

Bailliere Tindall, London.

Koch, T. 1973. Splanchnology. In Skold, B.H. and De Vries, L. (Eds): Anatomy of the Chicken and Domestic Birds, pp. 66-100. The lowa State University Press, Ames, lowa.

Liman, N., Bayram, G. and Koçak, M. 2001. Histological and histochemical studies on the lingual, preglottal and laryngeal salivary glands of the Japanese quail (Coturnix coturnix japonica) at the post-hatching period. -Anatomia 30: 367-373.

McLelland, J. 1975. Aves digestive system. In Getty, R. (Ed): Sisson and Grossman's The Anatomy of the Domestic Animals, pp. 1857-1882. W.B. Saunders Company, Philadelphia.

McLelland, J. 1979. Digestive system. In: King, A.S. and McLelland, J. (Eds): Form and Function in Birds, vol. 1, pp. 69-92. Academic Press, London.

McLelland, J. 1990. Digestive system. In A Colour Atlas of Avian Anatomy, pp. 47-65. Wolfe Publishing Ltd., Aylesbury, England.

McLelland, J. 1993. Apparatus digestorius [Systema alimentarium]. In: Baumel, J.J., King, A.S., Breazile, J.E., Evans, H.E. and Vanden Berge, J.C. (Eds): Handbook of Avian Anatomy: Nomina Anatomica Avium, 2nd edn. pp. 301-327. Nuttall Ornithological Club, Cambridge, Massachusetts.

McLeod, W.M. 1939. Anatomy of the digestive tract of the domestic fowl. -Veterinary Medicine 34: $722-727$.

McManus, J.F.A. 1946. Histological demonstration of mucin after periodic acid. -Nature (London) 158: 202.

Nickel, R., Schummer, A. and Seiferle, E. 1977. Digestive system. In Anatomy of the Domestic birds, pp. 40-61. Verlag Paul Parey, Berlin.

Porchescu, G. 2007. Comparative morphology of the digestive tract of the black African ostrich, hen and turkey, PhD thesis. Agrarian State University of Moldova, Moldova.

Ross, M.H. and Pawlina, W. 2006. Digestive system II: esophagus and gastrointestinal tract. In Histology. A Text and Atlas, 5th edn. pp. 518-575. Lippincott Williams and Wilkins, Philadelphia.

Saito, I. 1965. Comparative anatomical studies of the oral organs of the poultry. IV. Macroscopical observation of the salivary glands. - Bulletin of the Faculty of Agriculture, Miyazaki University 12: 110-120.

Samar, M.E., Avila, R.E., De Fabro, S.P., Porfirio, V., Esteban, F.J., Pedrosa, J.A. and Peinado, M.A. 1999. Histochemical study of Magellanic penguin (Spheniscus magellanicus) minor salivary glands during postnatal growth. Anatomical Record 254: 298-306.

Tabak, L., Levine, M., Mandel, I. and Ellison, S. 1982. Role of salivary mucins in the protection of the oral cavity. Journal of Oral Pathology 11: 1-17.

Tivane, C. 2008. A morphological study of the oropharynx and oesophagus of the ostrich (Struthio camelus), MSc dissertation. University of Pretoria, South Africa.

Tucker, R. 1958. Taxonomy of the salivary glands of vertebrates. - Systematic Zoology 7: 74-83.

Warner, R.L., McFarland, L.Z. and Wilson, W.O. 1967. Microanatomy of the upper digestive tract of the Japanese quail. -American Journal of Veterinary Research 28: 1537-1548.

Ziswiler, V. and Farner, D.S. 1972. Digestion and the digestive system. In Farner, D.S., King, J.R. and Parkes, K.C. (Eds): Avian Biology.pp. 344-354, Academic Press, New York. 